A Resource Consortium To Develop Interactive

Videodisc Training For Airway Sciences

William J. Shelt

Running Head: A Resource Consortium For Airway Sciences

99. 
Resource Consortium

1

Abstract

Increasingly, the responsibility for training the nation's aviation professionals will be that of collegiate Airway Science Curricula. One of the most effective methods for meeting growing demand in education is through computer aided instruction, most notably interactive videodisc training systems. While few observers can deny the benefits of interactive videodisc training, there are legitimate limitations to developing custom applications. An interactive videodisc training program typically requires a commitment of both information and financial resources. Educational institutions often find the requirements greater than they are able to provide individually. However, a consorted effort of universities, government agencies, and industry can develop a system which would be more sophisticated than any one group could develop alone. The first experiment examines the applicability of interactive videodisc training in aviation. The second is an experiment by educational institutions working together to create an interactive videodisc course. If the experiments show that interactive videodisc training has a place in aviation education, and that the cooperative efforts for developing courseware are possible, then the University Aviation Association is the ideal forum to coordinate an interactive videodisc project for Airway Science.

100. 


\section{A Resource Consortium To Develop Interactive Videodisc Training For Airway Sciences}

In a recent discussion with novice computer users, Dr. Richard Byrne warned, "Do not attempt to use computers to solve your problems." The astonished audience of aviation professionals listened to the computer science professor from the University of Southern California explain that the machines are simply tools which can help an organization become more productive. Computer technology is best utilized in areas of an organization where it is most proficient. "Computers can help you do the things you do well, even better." (Byrne, Note 1)

This idea is the foundation for using computer aided instruction in aviation training. The demand for well trained professionals in nearly all aviation fields is one of the most critical issues facing the industry. Traditional approaches for training people in aviation related fields have attempted to react to this need. The effort has been successful, but the need for training more people will continue. The future of aviation education is an ideal application of Dr. Byrne's message.

Greater demand for aviation personnel is primarily due to industry growth. Deregulation has allowed price competition among air carriers. Consumers have benefited from lower fares, and the cost of air travel has declined relative to other types of transportation. Overall demand for air service has increased, and the result has been more traffic in the airspace system.

101. 
The economic forces that have spawned more air traffic have had an obvious impact on the number of personnel required to service that need. When striking air traffic controllers were fired in 1981, the need for aviation professionals increased further. Replacement and expansion have caused a massive training effort by the Federal Aviation Administration (EAA). The need for more training has occurred in both the public and private sectors of aviation.

Airline pilots are being hired at an unprecedented rate, and more of the group is reaching mandatory retirement age. The training dilemma of meeting the greater demand for people with necessary skills has been compounded by declining supply at the same time. More military trained flight crews, maintenance technicians, and air traffic controllers have found the new programs for armed service personnel enticing enough to reenlist. The flight schools at fixed based operations that have trained so many general aviation pilots and maintenance personnel are suffering the effects common to general aviation. Despite the poor timing of surging demand and waning supply, the quality of the training received by professionals in the aviation industries has been extremely high. This is a credit to the organizations involved in aviation training, and is exemplified by the safety of the entire system.

Yet there are problems facing the aviation industry. The well publicized safety issues are ultimately reflected in those responsible for staffing the system. The pressure to assure safe air travel is not 
likely to subside. Many people feel the first step is to assure that those involved in the system continue to be well trained. Computer aided instruction can assist in the training of aviation professionals by helping trainers do what they do well, even better.

Interactive videodisc training, the form of computer assisted instruction that integrates full motion video, audio, three-dimensional animation, computer graphics, and text, is widely recognized as being one of the most effective instructional delivery systems. Caution is warranted for viewing interactive videodisc (IVD) training as a panacea for the problems facing educators. Interactive video cannot compete solely as a substitute for conventional means of instruction. Rather, it must compliment traditional methods in improving the overall effectiveness of teaching and/or training. (Kannan, 1986). There are benefits that extend to nearly all applications using the technology. However, the ultimate test of a technology's effectiveness in an industry segment is its acceptance by the users. The first experiment judges the potential for IVD applications in aviation training.

No system with the potential benefits of IVD is without limitations. One of those most often cited regarding interactive videodisc systems is the cost. Computer hardware and peripherals represent a relatively minor portion of an IVD training system's cost. The development cost of interactive videodisc courseware is the major expense in custom projects. 
Resource Consortium

Once development is complete, the cost of copies is miniscule.

Therefore, shared development costs can yield a synergistic effect to courseware creation. Those organizations that share the subject matter can have a course which is more effective than they would be able to produce individualiy with the same resources. The second study is an experiment in cooperation among educational institutions using interactive video to solve a common problem.

Cooperation in an environment as vicious as that currently exhibited in aviation may seem a remote concept to some observers. Regardless of whether the industry members are battling among themselves, or with government agencies, the common element among all participants in the system is the need for highly qualified, well trained professionals. The responsibility for providing the necessary training should be at the collegiate level. Vertical integration of colleges and universities that can offer aviation education will enable them to be the conduit between supply and demand of aviation professionals. A cooperative effort from industry, government, and universities can yield a highly effective training curriculum which benefits all participants. Initial steps toward this cooperative goal in aviation training have been taken. The University Aviation Association has formed a team of information sources to work with the Federal Aviation Administration to standardize a curriculum which will be used as a benchmark for Airway Sciences taught at universities throughout the country. Some airlines are anticipating 
the future demand by working with university placement office internship programs. The potential exists for a resource consortium to develop interactive videodisc courseware for Airway Sciences. The focal point of the consortium is the University Aviation Association. The participating universities will be able to expand their programs. Meanwhile, industry and government will be supplied with the quality of personnel they seek. Ultimately, the entire system will benefit through a safer system for air travel.

\section{Experiment 1}

\section{Method}

Subjects. One hundred-seventy-three pilots from a major U.S. airline participated in a demonstration and subsequent survey to determine their acceptance of interactive videodisc training. Their professional flying experience ranged from two to thirty-eight years with a mean of 14.8 years. The demonstration took place in the airline's pilot crewroom at one of its airport domiciles. All pilots based at that domicile received a brochure describing the experiment. Pilots participated in their time before, after, or between scheduled flights. The site was selected because of the volume of air traffic through that location, but the sample included pilots from various crew bases. The pilots who participated spent an average of twenty minutes examining IVD and ten minutes completing a questionnaire. The sample size represented approximately ten percent of the total pilot force of the carrier. The 
participants were told that their responses would be used in compiling a report to the carrier's management.

Apparatus. The equipment used in the demonstration was a level-three interactive videodisc system consisting of a microcomputer and videodisc player. The student station accepted inputs from a touch sensitive screen and had an option of speaker or headset for audio output. Three different demonstrations were available for the sample group. The first course was a wave soldering technique used in quality control for manufacturing circuit boards. This was an application of IVD for teaching psychomotor skills. The second demonstration emphasized cognitive skills in a management simulation game. The final demonstration course, and the one preferred by most participants, was course for teaching separation rules to air traffic controllers.

Procedure. Those pilots who were willing to participate in the demonstration were asked to work through one or more of the modules in the demonstration. Because no demonstration of specific pilot training courseware was available, the pilots were instructed to focus on the technological features of the delivery system rather than the courseware demonstrated. When the users felt they had a good understanding of the system's capabilities, they were given a questionnaire. A sample questionnaire is included in the appendix. Preliminary information about the sample group indicated that some of the pilots had been exposed to other types computer aided instruction. However, these systems lacked 
the motion video and audio features of IVD. The survey was designed to obtain the attitude of those who had never experienced any type of computer training, but also judge the attitude of those who could compare IVD to their previous exposure.

\section{Results}

The Babcock Graduate School of Management at Wake Forest University, Winston-Salem, NC, was selected to develop the survey questions and complete the analysis because of its excellent reputation and location. Overall, the pilots reacted favorably to the use of IVD as an instructional method. Of these pilots, 92.28 responded favorably or very favorably to the demonstration. Pilots who had previously experienced other computer-aided instruction, and pilots overall, significantly rated IVD higher than other computer-aided instruction in terms of the method being interesting, clear, well-paced, and easy to learn from.

\section{Mean Values}

Scale

Boring "1" to Interesting "7"

Confusing "1" to Clear "7"

Poorly Paced "1" to Well Paced "7"

Difficult to Learn "1" to Easy to Learn "7"

Pilots were asked to rate six factors that may contribute to the effectiveness of an instructional program. They were told to place a "1" next to the factor they felt was most important in their own case, a "2" 
next to the second most important fact, and so forth until they had marked all six factors. The mean values, ranked in order of importance by pilots, are found below.

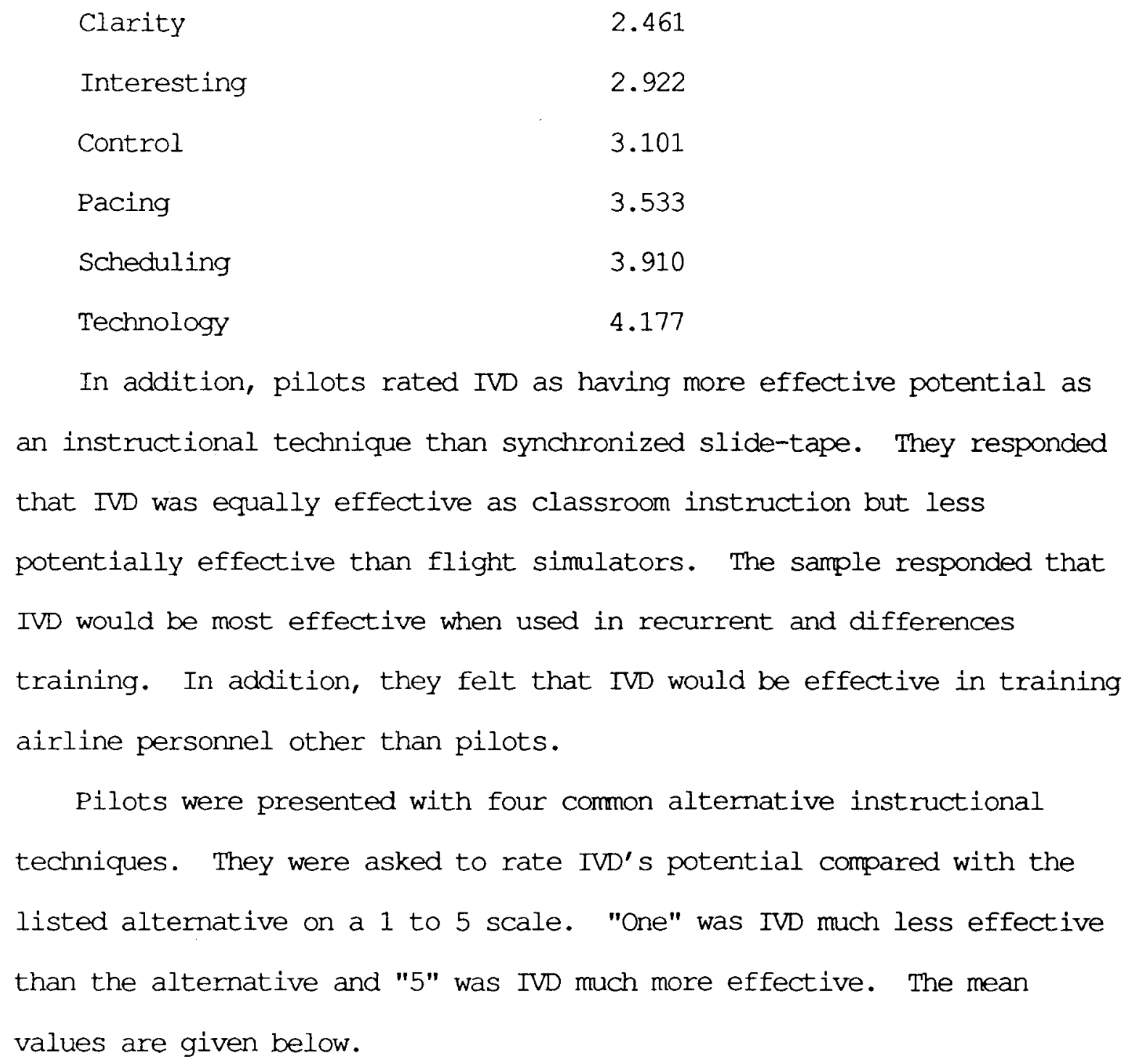

In addition, pilots rated IVD as having more effective potential as an instructional technique than synchronized slide-tape. They responded that IVD was equally effective as classroom instruction but less potentially effective than flight simulators. The sample responded that IVD would be most effective when used in recurrent and differences training. In addition, they felt that TVD would be effective in training airline personnel other than pilots.

Pilots were presented with four common alternative instructional techniques. They were asked to rate $\mathrm{IVD}^{\prime} \mathrm{s}$ potential compared with the listed alternative on a 1 to 5 scale. "One" was IVD much less effective than the alternative and "5" was IVD much more effective. The mean values are given below.

108. 
Instructional Alternative

Classroom instruction

Synchronized slide-tape

Flight simulators

Other computer-aided instruction
Mean Value

3.123

4.268

2.368

3.961

The results show that the pilots felt that IVD was more effective than synchronized slide-tape and other computer-based instruction. They responded that it was about equal to classroom instruction while it was potentially less effective that flight simulators. (Clapper, 1986)

Experiment 2

\section{Method}

Subjects. Eight school districts from the public school system in the state of Pennsylvania are involved in a program to provide a "Teacher Induction" interactive videodisc. School districts in the state are organized into Intermediate Units that serve as a super-structure for providing services to individual districts. These include, but are not limited to, media services, special education teachers, and facilities for assisting students with special requirements. There are twenty-nine Intermediate Units in the state. Intermediate Unit Number Thirteen (IU13) was targeted for the experimental development project. Of the twenty-three school districts within the IU13, a consortium of eight are participating in the project. There was no limit to the number of school districts that could participate. IU13 was selected because of its proximity to the courseware developers. 
Resource Consortium

11

Apparatus. The equipment specifications for the Teacher Induction courseware was designed to meet particular needs of the educational consortium. The members desired to utilize existing hardware if possible to minimize capital expenditures. All of the standard benefits of interactive videodisc systems needed to be incorporated. The most common type of computer equipment in the educational institutions is an Apple IIe microcomputer system. The system engineers determined that the computers could be reconfigured to make use of the installed base of hardware. The systems were designed to utilize a standard videodisc player and would have the touch sensitive monitor capability.

The Forum For Organization. The state of Pennsylvania mandates that certain programs are available in the public school system. One such program is a Teacher Induction course for all new teachers to become familiar with the methods of record keeping, discipline, and numerous general procedures that have traditionally been learned on the job. Recognizing that the methods which were being used by some of the school districts were not successful, the Technology Comittee of the IU13 met with an interactive videodisc procucer to explore the possibilities of developing a standard course.

A proposal was presented to the committee, curriculum coordinators, and superintendents of each district. Under the terms of the development agreement, the videodisc producer would forego its standard profit level and provide a program of higher value than the purchase price. In 
addition, the company would allow a flexible payment schedule for the schools. The course was recognized as having great market potential, but the goal was to solve problems within the participating districts.

\section{Results}

The goals of the experiment were common to all the consortium members: (a) First, the development of the course was designed to solve a problem. The school districts sought a solution to the state requirement for providing teachers with an induction to the school system. They recognized the problem, independent of the mandate, and saw IVD as an ideal solution. (b) Secondly, there was an opportunity for various sized school districts to interact with one another. Small school districts could learn from larger districts, and each could share unique problems. (c) The final goal centered on the technology itself. There is a good deal of positive public image surrounding those organizations that are involved with the latest technological advancements. The political nature of the public school system in most states makes officials aware of the need for such pursuits. In conjunction with that, the revenue generated from courseware sales in other districts would be shared with the development consortium. The IVD course would be seen by residents in the school district as an effective method to deliver the material, and a nontraditional altemative to funding public education. 
Resource Consortium

The overall results of the project are not known because development and marketing of the course are not complete. However, the initial interest and conmitment from the school districts is sufficient to begin development of the course. Each district is making the financial outlay necessary to fund the project, and providing the information, personnel, and facilities for production. (Davis, Note 2)

\section{Discussion}

The research presented in the experiments provides a foundation for inferences supporting the thesis. The first experiment was conducted to determine if interactive videodisc training had a place in aviation education. Many of the system's benefits seemed to be excellent adaptations of the technology, yet other touch-screen computer training systems were not received as well by the users. The results showed that the technological advancements that allowed an interactive audiovisual training system with database capabilities was an improvement that the users felt could be used in numerous aviation related applications.

The second experiment showed that a consortium of educational institutions with a common purpose found interactive videodisc training to be a delivery system that not only met their primary objectives, but yielded additional benefits as well. The technology is perhaps the most effective method of utilizing the schools' human, equipment, and financial resources. Their common purpose is not unlike the focus of the University Aviation Association.

112. 
While this primary research makes a very strong case for supporting an aviation education consortium utilizing interactive videodisc training, there is other information that leads one step closer to that conclusion. This existing data serves as secondary research for supporting involvement in the effort. The information pertains to the University Aviation Association's current cooperative effort, and the previous inclination of private sector involvement with universities.

The climate for cooperation exists in the University Aviation Association and it is exhibited in the organization's work in the Airway Science Curriculum. The curriculum was created by a comittee of educators working under the joint sponsorship of the Federal Aviation Administration and the University Aviation Association. (Naughton, 1986) The benefits of a standard curriculum to the UAA is that aviation education can be expanded or introduced at many universities. They can attract students to meet the demand for graduates in aviation fields. The FAA is committed to hiring a certain number of graduates, and benefits from hiring employees that have been through the curriculum which they sanctioned. The graduates hired by the FAA will enter at a higher salary grade than those not graduating from the Airway Science Curriculum. It should be noted that the Administration will not mandate how the courses are taught. According to Don Higgins, Manager of the Airway Science Curriculum project, the Administration will recognize universities that meet the "spirit and intent" of the curriculum. (Higgins, Note 3) 
The final element in the secondary research supporting the thesis is the involvement of airline industry participants. In a recent article regarding pilot training, Cliff Naughton, Associate Editor of Professional pilot magazine, discussed this opportunity.

While the major airlines appear still hesitant toward programs of coop education, work/study plans, and internships, and still shy away from even talking about sponsoring the training of lower time pilots, some are moving. (Naughton, 1986)

He cites examples of several carriers beginning to work with training institutions to bridge the pilot experience gap. Richard J. Ferris, Chairman of United Airlines, indicated his desire for input to the education process.

Newly licensed mechanics from fully accredited schools are well trained, but their skills would be more compatible with airline industry expectations if airlines advised technical schools of their needs, reviewed curricula, and evaluated apprentice programs.

(Ferris, 1986)

Involvement by air carriers has been sporadic and fragmented at this point. There is a great deal of pride and philosophical differences among the airline training departments. However, those who would support a resource consortium would have input to the methods of training. The long-term benefits of participation in a successful program would give them access to a source of graduates, and make the training within each carrier more efficient as graduates reach that level. 
Resource Consortium

\section{Conclusion}

Cooperation exists among members of the educational community in sharing information for standard curricula. Private and public sector leaders in aviation have demonstrated an understanding of the problems of training aviation professionals. The logical step is for the University Aviation Association to take the lead role in the concerted involvement of industry, government, and academia.

Many organizations for which training and education is a priority have found interactive videodisc training to be the most effective method for instructional delivery. Many of them face a similar imperative demand for skilled graduates that is needed in aviation professions. The large organizations that provide complete training services to corporate pilots have long known the benefits of interactive videodisc training systems to supplement their classroom and simulator time. The opportunity exists for universities to utilize this type of system by pooling their resources for development. An interactive videodisc training curriculum for Airway Sciences could be the binding element among the major participants in an airspace system that is in dire need of affordable efficient training and cooperation. 
Resource Consortium

17

\section{Reference Notes}

1. Byrne, Richard. Presentation at the National Air Transportation Association, Inc. Conference, March 1986.

2. Davis, Geoffrey L. Personal communication, June 1987.

3. Higgins, Donald. Personal communication, June 1987.

116. 
Resource Consortium

References

Clapper, James M. Pilot Attitudes Toward The Use of Interactive

Videodisc Technology. Wake Forest University, June 1986.

Ferris, Richard J. The Changing World of Work. United: The Magazine of the Friendly Skies, November 1986/7.

Kannan, Nat The True Power of Interactive Video: The Role of the Authoring Language. The Videodisc Monitor, July 1986.

Naughton, Cliff Producing The Professional Pilot, Professional Pilot, December 1986, pp 46-50.

117. 
Resource Consortium

\section{Figure Caption}

Figure 1. Pilot survey comparison of interactive videodisc and other computer aided instruction.

Figure 2. Pilot survey reaction to interactive videodisc training for aviation. 737-300 pilots represent those who have used other computer aided instruction. 


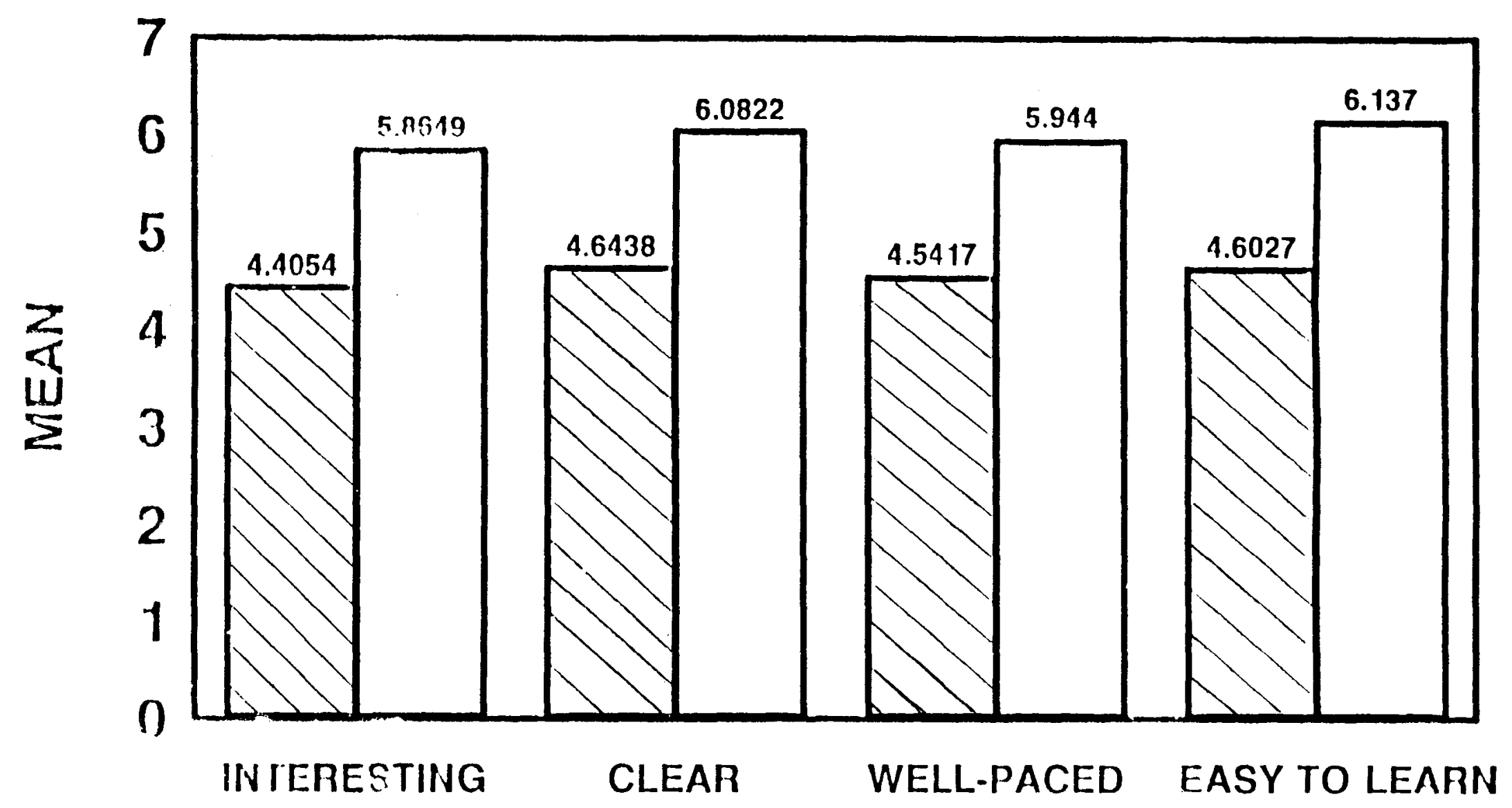

$\stackrel{\circ}{=}$ 
ALL PILOTS

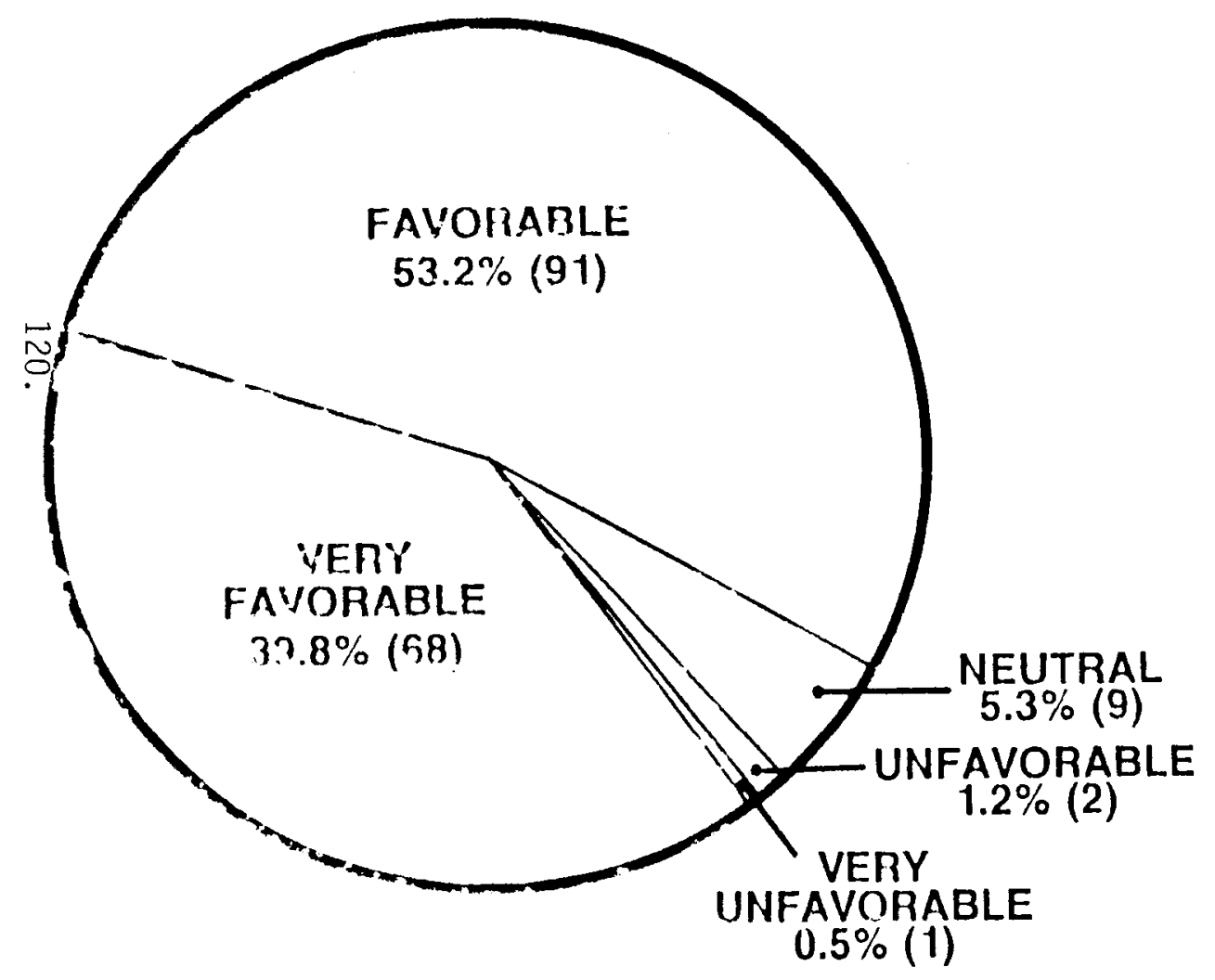

737-300 PILOTS

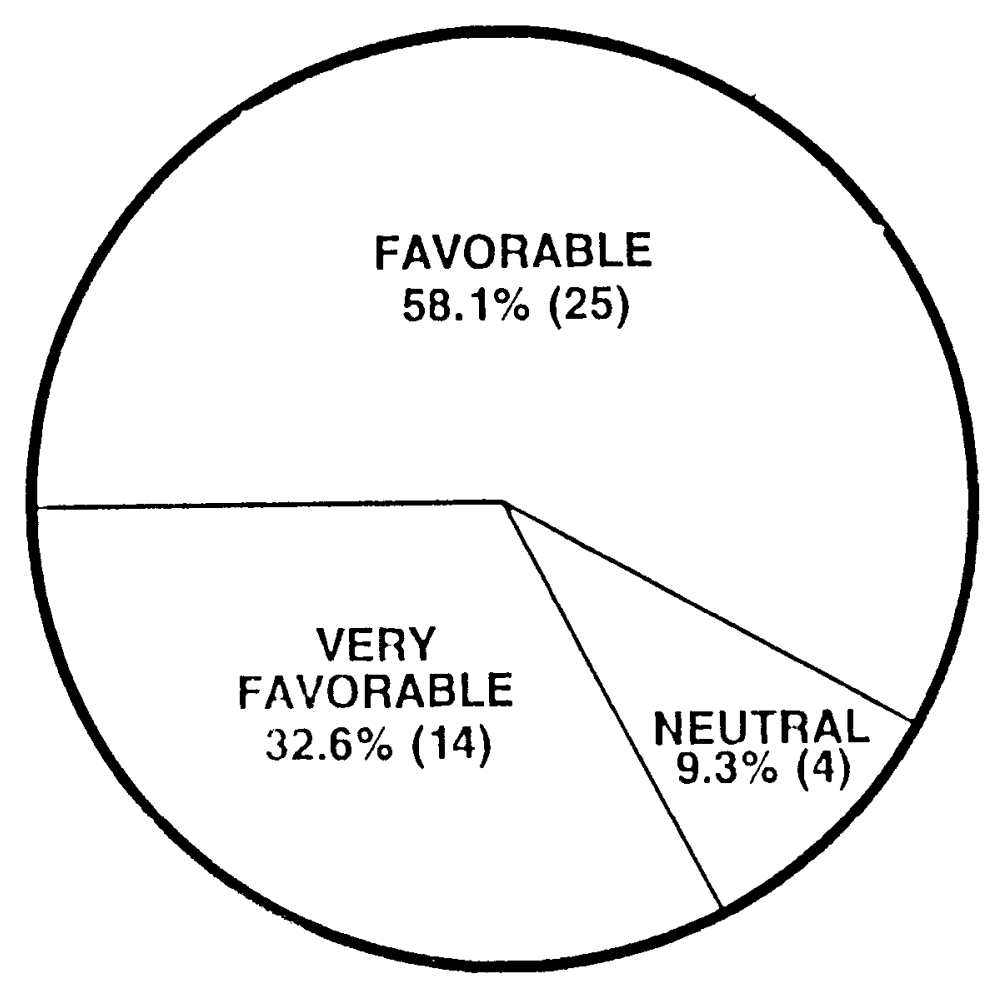

BI9M.3 
Resource Consortium

22

Appendix

Appendix A. Survey questionnaire used in the pilot opinion survey.

121. 